\title{
A Study of Causes and Factors Responsible for Maternal Mortality in a Tertiary Care Institute of Central Gujarat
}

\author{
Kanika P. Kachhwaha*, Mahima Jain \\ Department of Obstetrics and Gynaecology, Byramjee Jeejeebhoy Medical College \& Civil Hospital, Ahmedabad, Republic of India \\ Email address: \\ dr.kanikakachhwaha@yahoo.in (K. P. Kachhwaha) \\ ${ }^{*}$ Corresponding author \\ To cite this article: \\ Kanika P. Kachhwaha, Mahima Jain. A Study of Causes and Factors Responsible for Maternal Mortality in a Tertiary Care Institute of \\ Central Gujarat. Journal of Gynecology and Obstetrics. Vol. 7, No. 4, 2019, pp. 100-103. doi: 10.11648/j.jgo.20190704.11
}

Received: April 10, 2019; Accepted: June 4, 2019; Published: June 20, 2019

\begin{abstract}
Maternal mortality is still a big health concern in developing world. The state of maternal health represents overall state of women's right in health, social and economic realms. If the causes of death can be addressed and are found to be preventable it indicates negligence on the part of government and the entities that have the power to implement the changes. To determine factors and causes of maternal mortality this retrospective observational study was conducted in the department of obstetrics and gynaecology, BJ medical college. Maternal mortalities from October 2016 to March 2018 (18 months) were analysed with respect to factors like locality, literacy, parity, ANC care, time after admission, type of delay (according to maternal death review form) and causes of death (direct and indirect causes of MMR). Total 92 maternal deaths were studied and that gave a MMR of 468 per 1,00,000 live births. Maximum deaths occurred in patients who were in the age group of 20$34(83.1 \%)$, rural locality (71\%), Irregular with ANC visits (74\%), multigravida (56.5\%), within 24 hours of delivery (46.7\%) and those who had type 1 delay (delay in decision making to seek help, 78.3\%). More of deaths occurred in post partum $(84.8 \%)$ and in vaginal mode of delivery (47.4) Vs Caesarean section (46.3). Direct obstetric causes of death (57.6\%) were of deaths which included hypertensive disorders (29.3\%), haemorrhage (19\%) and others. Indirect causes accounted for $42.4 \%$ deaths which included hepatitis (21.7\%), heart diseases (9.8\%) etc. Early intervention and diagnosis with timely management are essential to reduce morbidity and hence maternal mortality. Special attention should be given to Routine Antenatal care (RANC) and more specifically to Focussed Antenatal Care (FANC)). Lack of expertise at primary level with lack of proper referral system adds to the cause.
\end{abstract}

Keywords: Maternal Mortality, Maternal Deaths, Gynaecology, Obstetric

\section{Introduction}

Every minute around the world, 380 women become pregnant, 190 face unplanned or unwanted pregnancies, 110 women experience pregnancy related complications, and 40 women have unsafe abortion and one woman die. [1] While major improvements have been made in infant mortality and total fertility rates in the past two decades, this has not been the case for maternal mortality. Maternal mortality and morbidity began to receive more attention in late 1980's with the publication of an article "Where is the $\mathrm{M}$ in $\mathrm{MCH}$ (Mother-Child health) and the introduction of safe motherhood initiative in 1987. [2] The decline of maternal mortality from past centuries is due to modern scientific understanding of causes of maternal mortality and adoption of practices which appear surprisingly simple in hindsight. [3]

Maternal mortality is unacceptably high. About 830 women die from pregnancy- or childbirth-related complications around the world every day. It was estimated that in 2015, roughly 3,03, 000 women died during and following pregnancy and childbirth. Almost all of these deaths occurred in 'low-resource settings', and most could have been prevented. [4]

India carries $25 \%$ of global burden of 5, 36,000 women dying of pregnancy related complications worldwide. [5] As per sample registration system (SRS), Registrar General of India, Maternal Mortality Ratio in India has shown a decline from 212 per 100,000 live births in the period of $2007-09$ to 178 per 100,000 live births in period 2010-12. [6, 7] According to NITI 
Ayog, India's maternal mortality reduced from 212 death per 1, 00,000 live births in 2007 to 167 deaths in 2013 and to 130 in 2016. This was mainly due to key government interventions like 'Janani Shishu Suraksha Karyakram' a nationwide maternal and child health programme launched in 2011. Between 2016 and 2030 as a part of sustainable development goals, target is to reduce global maternal mortality ratio to less than 70 per 1 , 00,000 live births.

However, in comparison to other developing and developed countries of the world India lies at the bottom as far as health outcomes are concerned. It is because of low public expenditure on determinants of health outcomes and also the loopholes in the existing health system. Therefore, if India has to achieve sustainable development goals by 2030 , health has to be at the centre stage of policy formation. [8]. Also, according to UN data the lifetime risk of maternal mortality in lower income country as a whole is 1 in 41 , compared to 1 in 3300 in high income countries. [9-11] According to UNICEF India, annually it is estimated that 44,000 women die due to preventable pregnancy related causes in India. While the increased attention has been clarified which interventions are more effective than others, the main challenge remains delivery of interventions to those areas of greatest needs.

The present study was conducted to review existing maternal mortality ratio \& causes of maternal deaths at tertiary care centre so that corrective steps can be taken.

\section{Methods and Materials}

\subsection{Type of Study}

A retrospective observational study.

\subsection{Place of Study}

This study was conducted in the department of obstetrics and gynaecology, BJ medical college.

\subsection{Duration}

Maternal mortalities from October 2016 to March 2018 (18 months) were analysed. Total 92 maternal deaths were noticed during this period and all were studied.

Data collected from cases were analysed, computed \& tabulated according to standard Performa \& details of live birth were collected from labour room register.

\subsection{Selection Criteria}

\subsubsection{Inclusion Criteria}

a) All patients who expired while pregnant or within 42 days of termination of pregnancy.

b) Any gestational age or site of the pregnancy.

c) All causes related to or aggravated by the pregnancy or its management.

\subsubsection{Exclusion Criteria}

Those who expired because of accidental causes.

Maternal mortalities were studied with respect to Socio- economic status, Residence/Locality (Rural or Urban), literacy, parity, ANC care, types of delay (Type-1 Delay in decision making, Type-2 Delay in transport, Type-3 Delay at institutional level) and causes of death (direct and indirect causes of maternal deaths).

\section{Results}

Table 1. Relationship between Maternal Age and Maternal Mortality.

\begin{tabular}{llll}
\hline $\begin{array}{l}\text { Maternal } \\
\text { Age }\end{array}$ & $\begin{array}{l}\text { Maternal } \\
\text { Deaths (n=92) }\end{array}$ & $\begin{array}{l}\text { Number of } \\
\text { live births }\end{array}$ & $\begin{array}{l}\text { Maternal Mortality } \\
\text { Ratio (Per 1 lac live } \\
\text { births) }\end{array}$ \\
\hline $15-19$ & $07(7.6 \%)$ & 1102 & 634 \\
$20-24$ & $23(25 \%)$ & 5925 & 388 \\
$25-29$ & $29(31.5 \%)$ & 6880 & 421 \\
$130-34$ & $25(27 \%)$ & 4954 & 504 \\
$35-39$ & $06(6.5 \%)$ & 702 & 854 \\
40 or more & $2(2.1 \%)$ & 102 & 1560 \\
Total & 92 & 4361 & 468 \\
\hline
\end{tabular}

Total 92 maternal deaths were noted during the study period. $(\mathrm{MMR}=468$ per 1 lac Live births). The largest number of maternal deaths $(83.1 \%)$ occurred in the age group of 20-34 but the MMR increased significantly in women with age more than 35 .

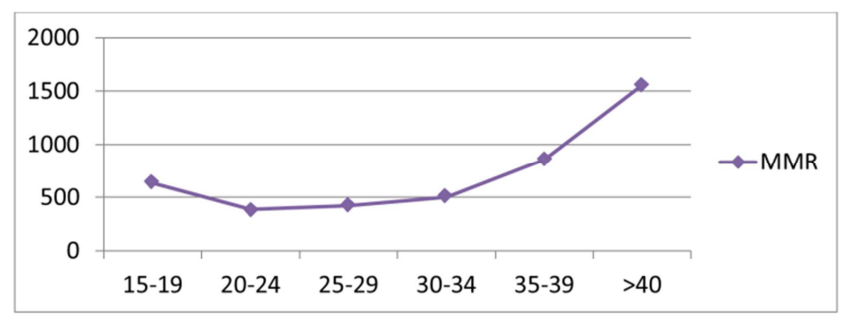

Figure 1. Relationship between Maternal Age and Maternal Mortality.

Early age group of 15-19 also showed higher mortality. This bimodal pattern can be seen i a "J" shaped graph.

Table 2. Relationship between Socio-Economical factors and Maternal Mortality.

\begin{tabular}{llll}
\hline Factor & & Number & Percentage \\
\hline \multirow{4}{*}{ Education } & Illiterate & 41 & $45 \%$ \\
& Primary & 28 & $30 \%$ \\
& Secondary & 15 & $16 \%$ \\
Residence & Above Secondary & 8 & $09 \%$ \\
& Rural & 65 & $71 \%$ \\
Economic & Urban & 27 & $29 \%$ \\
Status & Lower & 60 & $65 \%$ \\
& Middle & 26 & $28 \%$ \\
Gravida & Upper & 06 & $07 \%$ \\
& Primi & 32 & $34 \%$ \\
& Multi (2-4) & 52 & $57 \%$ \\
\hline
\end{tabular}

Table 3. Relationship between Type of delay and Maternal Deaths.

\begin{tabular}{lll}
\hline \multirow{2}{*}{ Type of Delay } & \multicolumn{2}{l}{ Maternal Deaths } \\
\cline { 2 - 3 } & Numbers & Percentage \\
\hline Type 1 (Delay in decision making to seek & 72 & $78.30 \%$ \\
help) & 15 & $16.30 \%$ \\
Type 2 (Delay in transport) & 05 & $06.40 \%$ \\
Type 3 (Delay at Institutional level) & & \\
\hline
\end{tabular}


Table 4. Underlying causes of maternal mortality.

\begin{tabular}{|c|c|c|c|c|}
\hline \multirow{3}{*}{ Cause } & \multicolumn{4}{|c|}{ Maternal Deaths } \\
\hline & \multicolumn{2}{|c|}{ Present study } & \multirow{2}{*}{ Surekha et al 2017[2] } & \multirow{2}{*}{ Nair et al 2016[3] } \\
\hline & Deaths & Percentage & & \\
\hline Direct Cause & 53 & 57.60 & 50.90 & 58.90 \\
\hline Eclampsia & 27 & 29.30 & 29.80 & 28.80 \\
\hline Haemorrhage & 19 & 20.60 & 12.10 & 11.10 \\
\hline Septic abortion & 03 & 03.30 & 07.60 & 07.30 \\
\hline Ruptured uterus & 02 & 02.20 & - & - \\
\hline Amniotic Fluid embolism & 01 & 01.10 & 01.28 & 02.20 \\
\hline Puerperal sepsis & 01 & 01.10 & - & 05.10 \\
\hline Ectopic pregnancy & - & - & - & 04.40 \\
\hline Indirect causes & 39 & 42.40 & 49.10 & 41.10 \\
\hline Hepatitis & 20 & 21.70 & 14.10 & 15.90 \\
\hline Heart diseases & 09 & 09.80 & 08.10 & 13.30 \\
\hline Anaemia & 03 & 03.30 & 02.60 & - \\
\hline H1N1 influenza & 03 & 03.30 & 10.10 & 06.50 \\
\hline Cerebral malaria & 01 & 01.10 & 02.60 & 01.20 \\
\hline Other indirect causes & 03 & 03.30 & 09.00 & 05.40 \\
\hline
\end{tabular}

Table 5. Maternal Mortality Ratio.

\begin{tabular}{lllll}
\hline Total number of live & Total number of maternal & Maternal Mortality Ratio & & \\
\cline { 2 - 4 } births during study period & deaths & Present study & Surekha et al 2017 & Nair et al 2016 \\
\hline 19655 & 92 & 468 & 518 & 544 \\
\hline
\end{tabular}

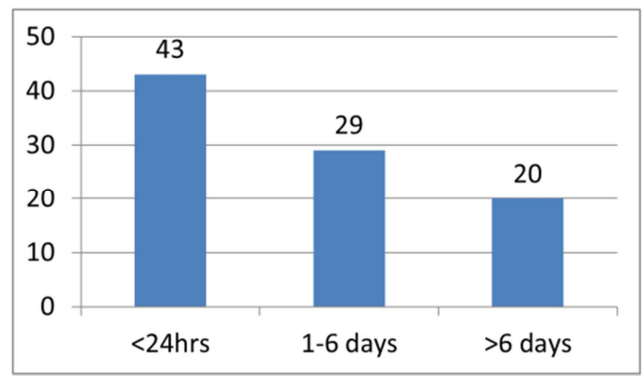

Figure 2. A graph showing time interval from admission to death.

\section{Discussion}

The largest number of deaths occurred in the age group of 20-34, largely because those are the ages at which women are most likely to give birth, so efforts directed at this age group would most effectively reduce the number of deaths.

Women aged less than 19 years and more than 40 years had maternal mortality ratios of 634 and 1560 per $1,00,000$ live births respectively. The age distribution of maternal mortality ratio is comparable to the Ann K. Blank et al 2016 study. The risk of maternal mortality is highest for adolescent girls under 15 years old and complications in pregnancy and childbirth is a leading cause of death among adolescent girls in developing countries. $[12,13]$ A young pregnant woman carries higher risk due to preeclampsia, cephalopelvic disproportion, uterine inertia and anemia. In elder women there are raised chances of diabetes, preeclampsia, postpartum and antepartum haemorrhage.

Poverty influences a woman's utilisation of health services and also has indirect effects on her general health by way of malnutrition. Unawareness about contraceptive measures and high fertility rates also account for the mortalities in these women.

Considering the type of delay, type 1 delay was commonest and type 3 was least common. Similar results were found in studies by surekha et al and Nair et al. [14, 15] It shows patient's and caregiver's inability to recognise that an abnormal condition exists, that the condition has a level of severity warranting intervention and that an intervention is available to treat the condition. Traditional birth attendants should be trained to take deliveries safely and also be able to identify 'danger signs', which must prompt timely transfer of a woman to the nearest health facility.

A big chunk of deaths occurred within $24 \mathrm{hrs}$ of admission. Eclampsia, haemorrhage and hepatitis accounted for $72 \%$ of deaths that occurred in first $24 \mathrm{hrs}$. Early seeking of help and early diagnosis of mentioned conditions could have prevented many deaths.

Hypertensive disorders and haemorrhage together accounts for $49.9 \%$ of total maternal deaths in the present study. The figure reflects the suboptimal standards of obstetric care received in many cases. Although the maternal deaths were in a tertiary hospital, their problems and initial management often started in smaller hospitals or periphery maternal units. Despite the availability of magnesium sulphate for prophylaxis and treatment of eclamptic seizures, the rates of eclamsia and its complications still remain very high. The mortalities due to puerperal sepsis and septic abortions are falling due to legalisation of abortions, clean deliveries, antenatal tetanus immunisation and availability of higher antibiotics.

Among the indirect causes, Hepatitis causes $21.7 \%$ of deaths in this study. Non availability of safe drinking water, unhygienic living conditions and the fulminant nature of hepatitis $\mathrm{E}$ in pregnancy explains the disproportionate number of deaths by hepatitis in pregnant women. Cardiac 
conditions caused 9 maternal deaths in this study. Women with pre-existing heart conditions should be assessed prepregnancy with the aim of optimizing the clinical state. During pregnancy a multidisciplinary team should define the level of care required in each case.

Anemia led to only $3.3 \%$ deaths in this study despite the high prevalence. It is explained by the fact that anemia rarely causes death on its own. Anemia was the contributing factor in 22 deaths which is $23.9 \%$.

\section{Conclusion}

Almost 50\% were indirect medical causes like hepatitis, cardiac diseases, anaemia and communicable diseases. Proper sanitation measures, eliminating communicable diseases and availability of portable drinking water can prevent these.

Regular ANC visits, early screening of high risk pregnancies, adequate nutrition to mothers, improvement in education level and socioeconomic status are also important areas which need more focus.

Most maternal deaths can be prevented if births are attended by skilled health personnel- doctors, nurses and midwives- who are regularly supervised, have proper equipment and supplies, and can refer women in a timely manner to emergency obstetric care when complications are diagnosed.

There is no silver bullet policy to address issue of maternal mortality. Proper implication of NRHM programmes, improvement in primary healthcare in rural areas and up gradation of hospitals in rural areas can bring down the number of maternal deaths.

\section{Competing Interests}

All the authors do not have any possible conflicts of interest.

\section{References}

[1] Inter-Agency Group for Safe Motherhood. Safe Motherhood: Helping to make women's reproductive health and rights a reality. Family Care International. New York. 1998. P. 2.

[2] Gülmezoglu AM, Say L, Betrán AP, Villar J, Piaggio G. WHO systematic review of maternal mortality and morbidity: methodological issues and challenges. BMC Med Res Methodol. 2004; 4: 16. Published 2004 Jul 5. doi: 10.1186/1471-2288-4-16.
[3] Max Roser and Hannah Ritchie (2019) - "Maternal Mortality". Published online at OurWorldInData.org. Retrieved from: 'https://ourworldindata.org/maternal-mortality' [Online Resource].

[4] Global, regional, and national levels and trends in maternal mortality between 1990 and 2015, with scenario-based projections to 2030: a systematic analysis by the UN Maternal Mortality Estimation Inter-Agency Group. Alkema L, Chou D, Hogan D, Zhang S, Moller AB, Gemmill A, et al. Lancet. 2016; 387 (10017): 462-74.

[5] Khandale SN et al. Int J Reprod Contracept Obstet Gynecol. 2017 Apr; 6 (4): 1610-1613.

[6] United Nations Development Programme. Millenium Development Goals.

[7] Betran AP, Wojdyla D et al, Maternal mortality at country level: an analysis based on WHO systemic review. BMC public health 2005; 5: 131 .

[8] Raina, Shahid Hamid, India's Health Status and Sustainable Development - Achievements and Challenges (March 17, 2017).

[9] Rudan I, Lawn J et al. Gaps in policy-relevant information onburden of diseases in children: A systemic review. Lancet 2005; 365: 2031-40.

[10] Glaziou P, Irvig L, Bain C, Colditz G. Frequency and rate. In: Systemic reviews in health care: a practical guide, $2^{\text {nd }}$ edn. Cambridge, UK: Cambridge University Press, 2001: 67-73.

[11] Stroup DF, Berlin JA, Morton SC, Oikin I et al. Meta-analysis of observational studies in epidemiology. A proposal for reporting. JAMA 2000; 283: 2008-12.

[12] Maternal-perinatal morbidity and mortality associated with adolescent pregnancy in Latin America: Cross-sectional study. Conde-Agudelo A, Belizan JM, Lammers C. American Journal of Obstetrics and Gynecology, 2004, 192: 342-349.

[13] Global patterns of mortality in young people: a systematic analysis of population health data. Patton GC, Coffey C, Sawyer SM, Viner RM, Haller DM, Bose K, Vos T, Ferguson J, Mathers CD. Lancet, 2009, 374: 881-892.

[14] Khandale SN, Kedar K. Analysis of maternal mortality: a retrospective study at tertiary care centre. Int J Reprod Contracept Obstet Gynecol 2017; 6: 1610-3.

[15] Nair A, Doibale MK, Gujrathi VV, Inamdar IF, Shingare AD, Rajput PS. Study of maternal mortality in a tertiary care hospital in a district of Maharashtra. Int J Med Sci Public Health 2016; 5: 1851-1854. 